\title{
Research of the Relationship between Partial Discharge and Gas Decomposition Products in $\mathrm{SF}_{6}$ Insulated Equipment
}

\author{
Gang Lu, Yang Liu \\ Heilongjiang Electric Power Research Institute, Xiangfang District 150036, Harbin, P.R. China \\ e-mail: 13163417178@163.com
}

\begin{abstract}
In order to analyze the gas decomposition products under partial discharge by quality and by quantity, designed a $126 \mathrm{kV}$ AC industrial frequency power supply, a GIS partial discharge testing platform and a gas detection system, simulated the fault model of ground discharge, used pulse current method on discharge intensity monitor, concluded the characteristic of the concentrations of decomposition as well as its change in concentrations over time. The experimental results indicate that: $\mathrm{SF}_{6}$ gas decomposed into $\mathrm{SOF}_{2}, \mathrm{SO}_{2}$, $\mathrm{S}_{2} \mathrm{OF}_{10} ; \mathrm{SOF}_{2}, \mathrm{SO}_{2}$ under partial discharge, this procedure has positive correlation with PD duration and partial discharge severity, adsorbent also has effects to the decomposition products.
\end{abstract}

Keywords-partial discharge; $\mathrm{SF}_{6}$; decomposition components; gas analysis; defect

\section{INTRODUCTION}

Most of the common features of electrical fault always accompanied by partial discharge effect, inner defects caused the distortion of the electric field, leading to the uneven of electric field distribution, resulting in the appearance of partial discharge. Partial discharge is the main reason of insulation deterioration. The most commonly used method of fault diagnosis is detecting the process of partial discharge of the device. In general, the existence of the internal insulating defects can be found and confirmed. This measure has important practical significance to ensure safe and reliable operation of the grid. Specific methods includes frequency domain analysis, UHF, ultrasonic method; common methods such as pulse current law, UHF and ultrasonic method has been widely used and has the characteristics of simple and fast, on the other hand it is easily effect by the electromagnetic field near the measuring environment and interfered by noise, and it is also difficult to quantify the partial discharge, which means hard to estimate the state of the equipment insulation.

$\mathrm{SF}_{6}$ gas has high electric strength, excellent arc performance, stability, chemical resistance and other characteristics. It's widely used in power devices. Most electrical equipment failure was caused by partial discharge while partial discharge in turn causes decomposition of $\mathrm{SF}_{6}$ gas, gaseous decomposition products react chemically with metallic material arc chamber, gas chamber metal material and solid insulation materials to form metal fluoride, metal sulfide, metal oxides and sulfur fluorides, such as $\mathrm{SF}_{4}$, $\mathrm{SOF}_{2}, \mathrm{SO}_{2} \mathrm{~F}_{2}$ and $\mathrm{SOF}_{4}$, etc. Studies have shown that, due to the presence of moisture in $\mathrm{SF}_{6}$, these substances occurs hydrolysis reaction to form thionyl substances, thus decomposition characteristics could be use to detect $\mathrm{SF}_{6}$ gas component of its content to determine the internal state of the device. Thus the use of $\mathrm{SF}_{6}$ gas decomposition characteristics to achieve the research on-line monitoring and fault diagnosis is on the rise.

The present experiment applied a self-designed $126 \mathrm{kV}$ GIS AC power frequency and partial discharge test platform to simulation discharge fault analysis with gas detection systems to monitor $\mathrm{SF}_{6}$ decomposition due to partial discharge, both qualitative and quantitative analysis were applied, using pulse current method for monitoring intensity of partial discharge. Acquired the characteristic of the concentrations of decomposition as well as its change in concentrations over time. Provided technical supply for further research of $\mathrm{SF}_{6}$ decomposition analysis, especially for the device state diagnostic and fault detection.

\section{GIS PARTICIAL DISCHARGE TEST ENTITY}

\section{A. Experimental Platform}

1) Experimental apparatus.

To study the laws of $\mathrm{SF}_{6}$ decomposition products produced with partial discharge and correlation factors, particularly design and manufactured a $126 \mathrm{kV}$ GIS experimental platform for the simulation of various type of fault. Structure of the platform is shown in figure 2-1. Set all kinds of failure modes, with digital PD detector, real-time monitoring change of PD intensity during the experiment. 


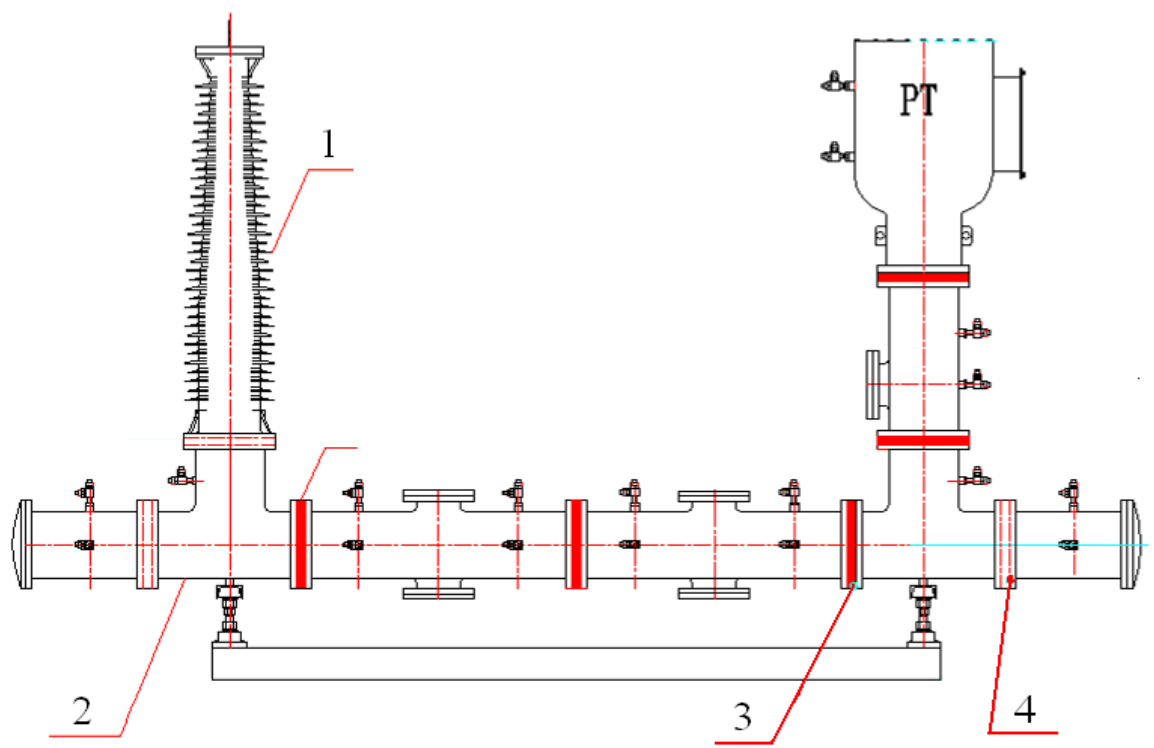

Figure 1. 126kV GIS fault simulation equipment

1. Silicon rubber casing, 2.3.4. Insulator

\section{2) Test circuit.}

According to the literature, $\mathrm{SF}_{6}$ decomposition experiments PD devices mostly applying frequency high voltage test power supply, in order to acquire the true circumstance of the discharge of the defect, simulating the actual operating conditions of the power grid. Unlike this model, our test circuit uses $50 \mathrm{~Hz}, 126 \mathrm{kV}$ direct boost power supply no halo voltage test system, which is characterized by the output current of the industrial frequency, test system itself has small amount of partial discharge, isolation transformers were set between each unit to guarantee a better anti-interference performance, which has nearly the same performance as the grid's actual operation conditions, thus ensuring the authenticity of the experimental study.

Partial discharge measurement: under experimental condition, partial discharge strength of faulted GIS device was measured synchronously by a system based on pulsed current method. In this experimental system, the background noise is less than $5 \mathrm{pC}$, and we specially designed non-PD current limiting resistance.

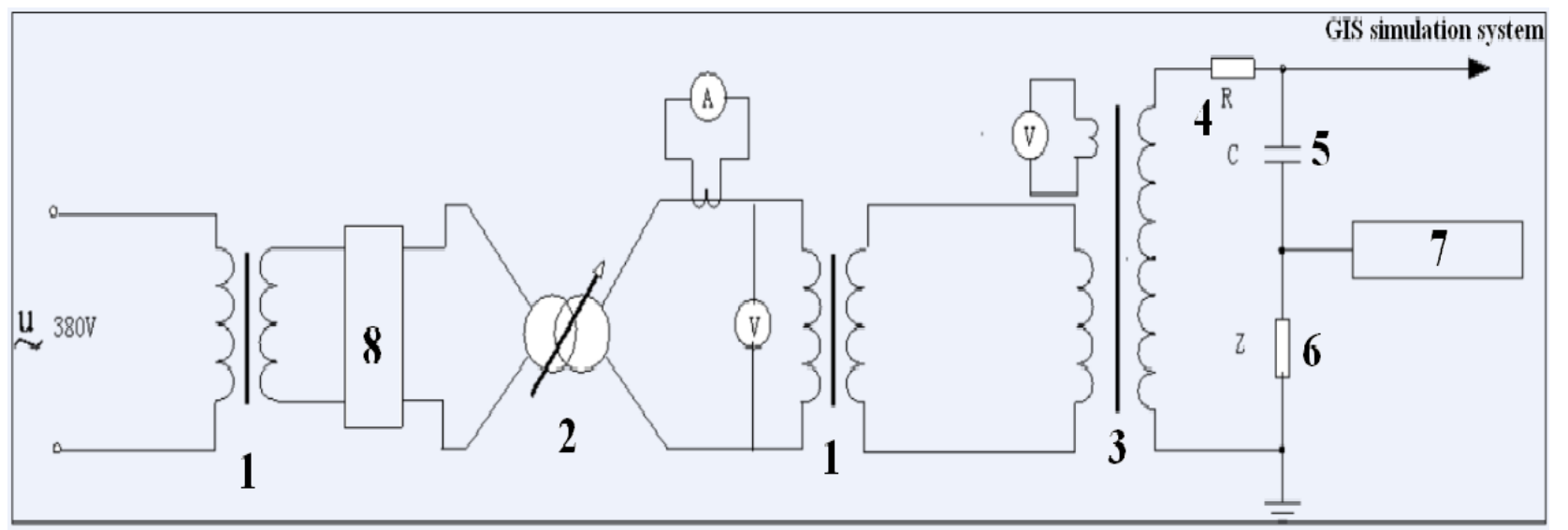

Figure 2. Test circuit

1.Isolate transformer 2.Voltage regulator 3.No-halo transformer 4.Protecting insulator 5.Coupling capacitance 6.Measured impedance 7.PD apparatus 8.Control console

3) SF6 gaseous decomposition detection system

- Gas chromatography analysis system

Detector: Parallel TCD, FPD detector; chromatographic column: GsBP-GASPRO $60 \mathrm{~m} \times 0.32 \mathrm{~mm}$ $\times 5.00 \mu \mathrm{m}$; (connecting FPD)

GsBP-GASPRO $30 \mathrm{~m} \times 0.32 \mathrm{~mm} \times 5.00 \mu \mathrm{m}$; (connection 
TCD) Injection system: automatic injection valve, split

injection (both deactivated inert valves)

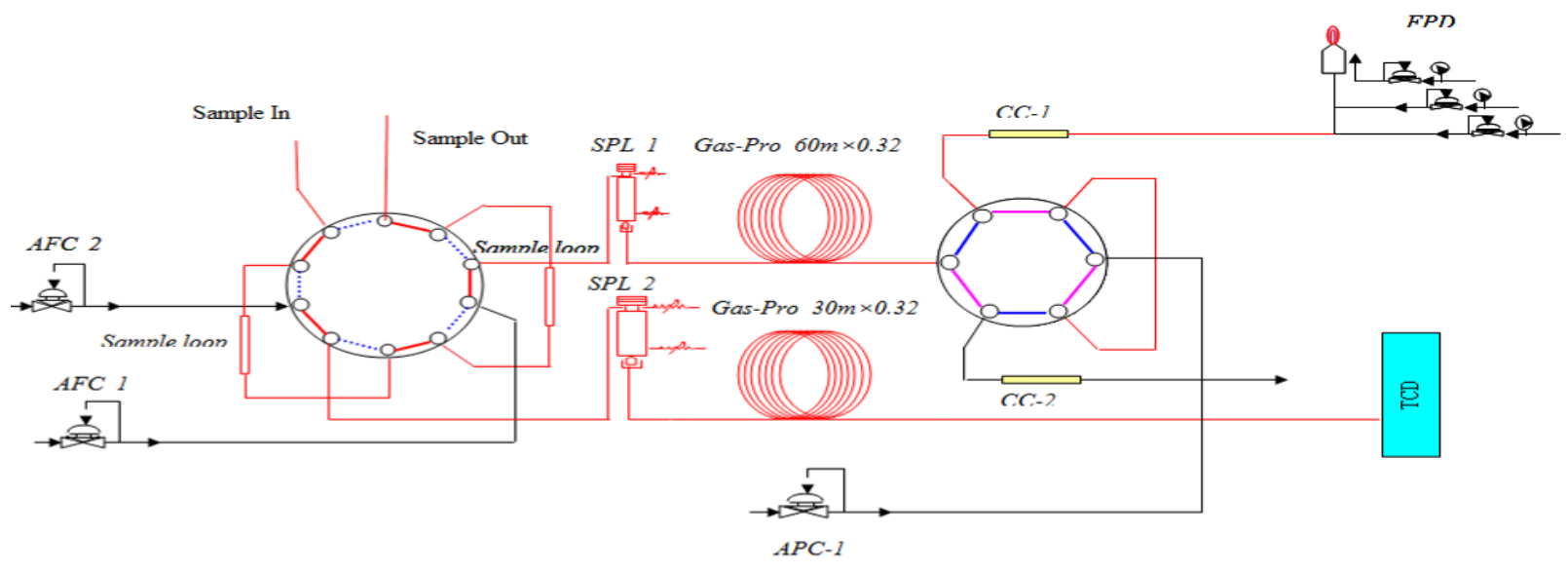

Figure 3. Process of gas chromatographic analysis

- Gas chromatography - mass spectrometry analysis system

Detector: MS;

Column: GsBP-GASPRO $60 \mathrm{~m} \times 0.32 \mathrm{~mm} \times 5.00 \mu \mathrm{m}$;

Injection system: manual injection valve, split injection.

\section{B. Experimental Procedure}

Setting bus-bar spikes on fault mode of GIS shell discharge, pressure of $\mathrm{SF}_{6}$ was $0.42 \mathrm{MPa}$, moisture content levels in equipment is within the scope of operating eligibility. Regulate the discharge voltage to achieve a stable partial discharge, continuous recording potential value and partial discharge; recording experimental time.

The gas sampling employing three ways: direct sampling, automatic sampling equipment and sampling cylinder. $\mathrm{SF}_{6}$ decomposition component was measured by gas chromatography and GC-MS, both analyses of qualitative and quantitative methods was applied in the course of the experiment. The interval of gas measurement sampling is 1 hour.

\section{EXPERIMENTAL RESULTS}

\section{A. Relationship between Partial Discharge and Gas Pressure}

Modify the $\mathrm{SF}_{6}$ gas pressure at the range of $0.1 \sim$ $0.4 \mathrm{MPa}$, detect the initial discharge voltage and partial discharge strength, results shown in Figure 4 and 5, they show that the density of $\mathrm{SF}_{6}$ increase with the pressure increasing, a negative relationship exists between the initial discharge voltage and partial discharge strength.

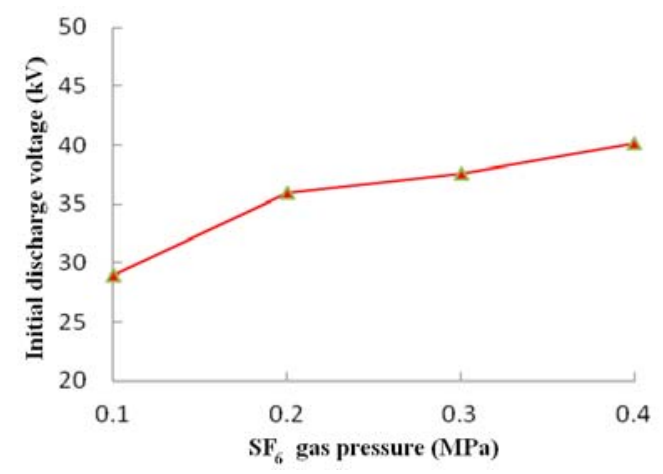

Figure 4. Initial discharge voltage against SF6 gas pressure

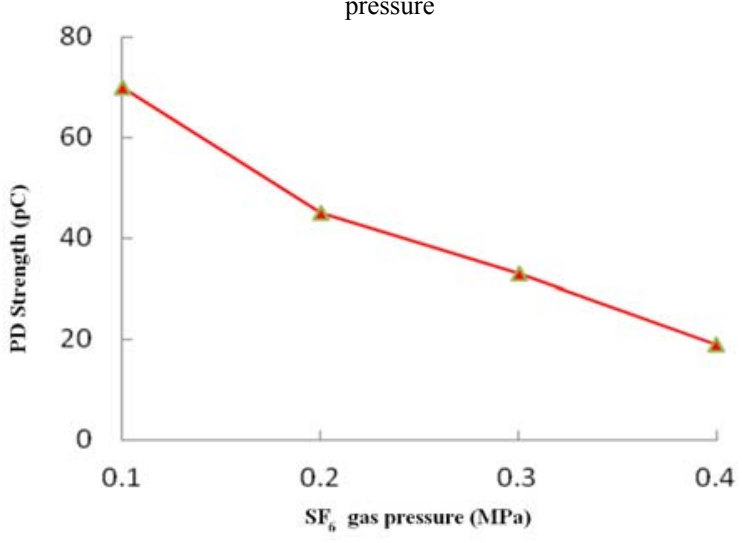

Figure 5. Partial discharge strength against SF6 gas pressure

\section{B. Experimental Study without Adsorbent}

In the partial discharge experiment platform, set bus-bar spikes on fault mode of GIS shell discharge without installation of absorbent. $\mathrm{SF}_{6}$ gas pressure is set to $0.11 \mathrm{MPa}$ and $0.21 \mathrm{MPa}$, test voltage is applied to carry out the partial 
discharge experiment. Detect the variation of main $\mathrm{SF}_{6}$ decomposition products during the partial discharge procedure.

1) Relationship between partial discharge strength and main product of $\mathrm{SF}_{6}$ decomposition

Experimental conditions: gas pressure: $0.11 \mathrm{MPa}$, gas humidity: $114.68 \times 10-6$ (volume fraction concentration), chamber volume: $0.07 \mathrm{~m}^{3}$, corresponding partial discharge under relatively stable conditions, discharge time: $1 \mathrm{~h}$.

PD experiment discharge gap is fixed, by adjusting the test voltage, resulting in different partial discharge strength, detecting different $\mathrm{SF}_{6}$ decomposition components $\left(\mathrm{SOF}_{2}\right.$, $\begin{array}{llll}\mathrm{S}_{2} \mathrm{OF}_{10} & \text { and } & \left.\mathrm{SO}_{2}\right) & \text { under }\end{array}$

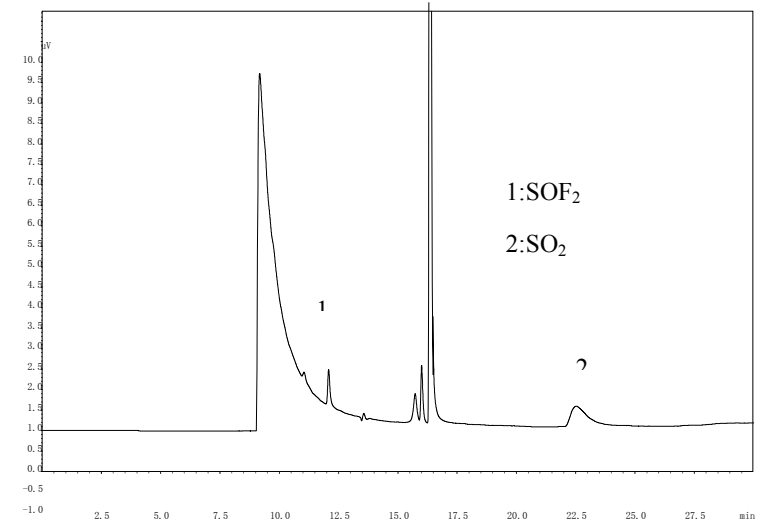

Figure 6. SF6 decomposition gas chromatogram

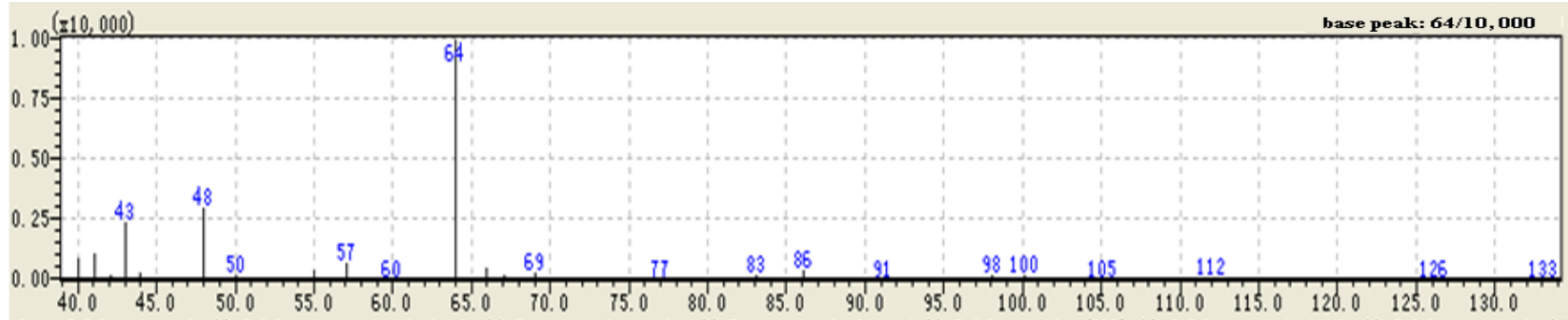

64 : Sulfur dioxide $\$ \$$ Sulfurous acid anhydride $\$$ Permenicide porder $\$$ Permenticide liquid $\$$ Sulfur oxide $(S 02) \$$ Sulfurous anhydride $\$ \$$ Sulfurous oxide $\$ \mathbb{N}$

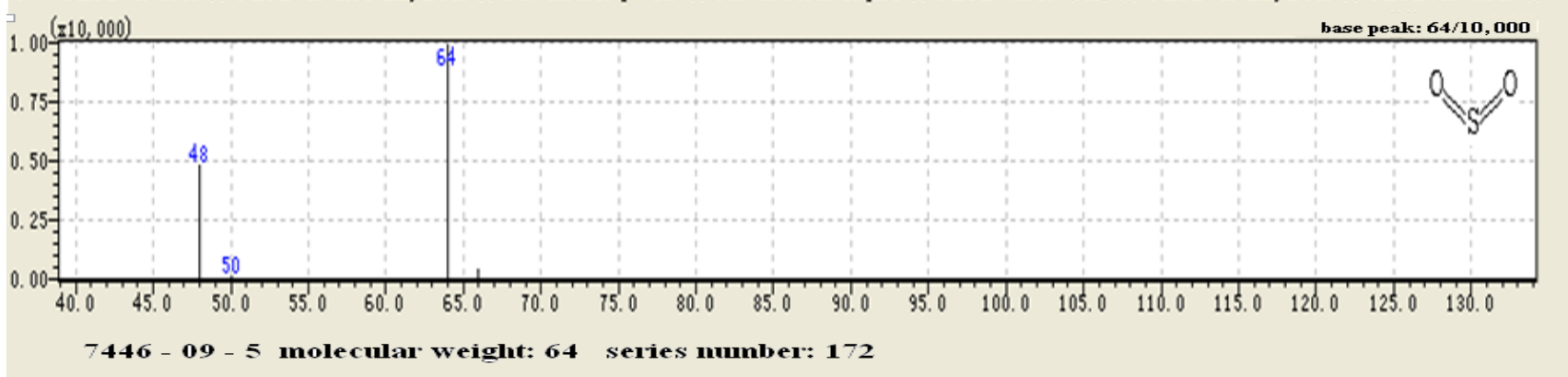

Figure 7. SF6 decomposition substance spectrum

Discharge voltage is maintained at $30 \sim 40 \mathrm{kV}$, partial discharge strength increases linearly; background of $\mathrm{SF}_{6}$ gas exists Air and $\mathrm{S}_{2} \mathrm{OF}_{10}$, no $\mathrm{SOF}_{2}$ and $\mathrm{SO}_{2}$; the $\mathrm{SO}_{2}$ concentration increased along with the partial discharge strength rendering similar changes shown in Figure 8. Concentration of $\mathrm{SOF}_{2}$ and $\mathrm{S}_{2} \mathrm{OF}_{10}$ contents experience a slight increase with partial discharge shown in Figure 9, Figure 10.

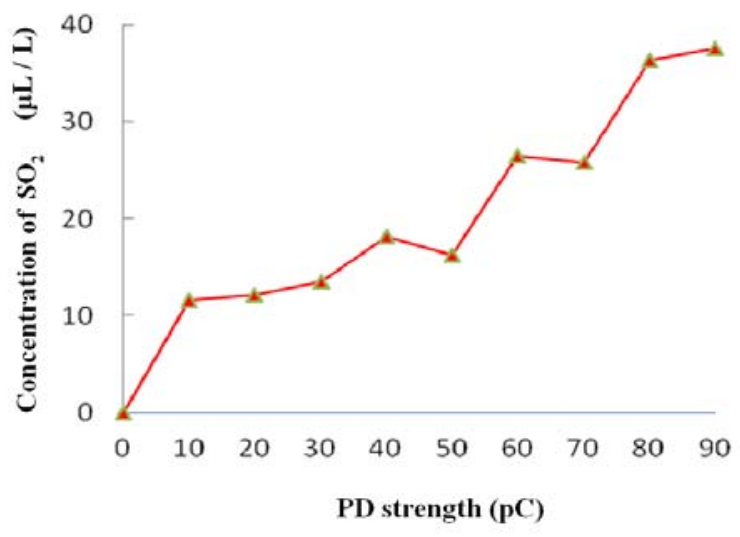

Figure 8. Concentration of SO2 against partial discharge strength under pressure $0.11 \mathrm{MPa}$ (correspond discharge time $1 \mathrm{~h}$ ) 


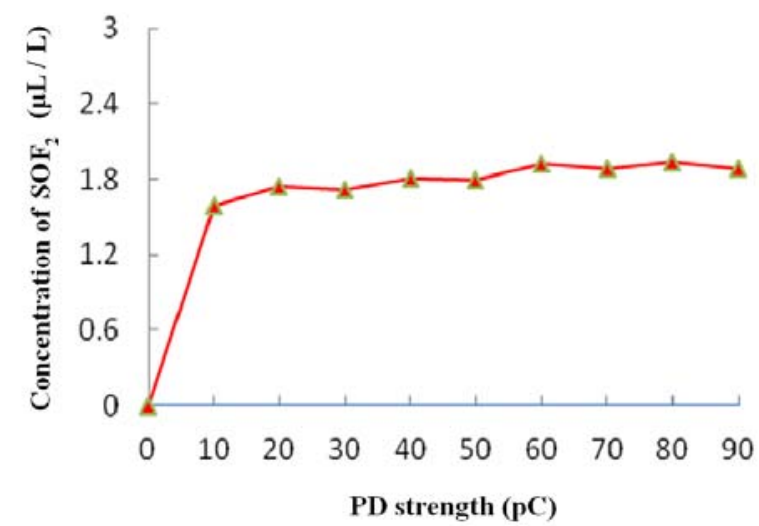

Figure 9. Concentration of SOF2 against partial discharge strength under pressure $0.11 \mathrm{MPa}$ (correspond discharge time $1 \mathrm{~h}$ )

According to Figure 8 and 9, the result shows that partial discharge experiment production $\mathrm{SOF}_{2}$ is $1.59 \sim$ $1.89 \mu \mathrm{L} / \mathrm{L}$, augment with the increase of partial discharge strength. The content has greater augmentation in the initial experiments, as partial discharge continue the upward trend is slowed; relationship between $\mathrm{S}_{2} \mathrm{OF}_{10}$ and partial discharge strength appear to be the same trend with $\mathrm{SOF}_{2}$. As the partial discharge strength augments, the production slightly increase by $0.1 \mu \mathrm{L} / \mathrm{L}$; by analysis the relationship between partial discharge strength and the concentration of $\mathrm{SO}_{2}$, the results show that large amount of $\mathrm{SO}_{2}$ is produced during the partial discharge experiment, these increases shows a linear growth trend, the range of concentration remains within $11.55 \sim 37.62 \mu \mathrm{L} / \mathrm{L}$. In conclusion, the main production is $\mathrm{SO}_{2}$ and less $\mathrm{SOF}_{2}$.

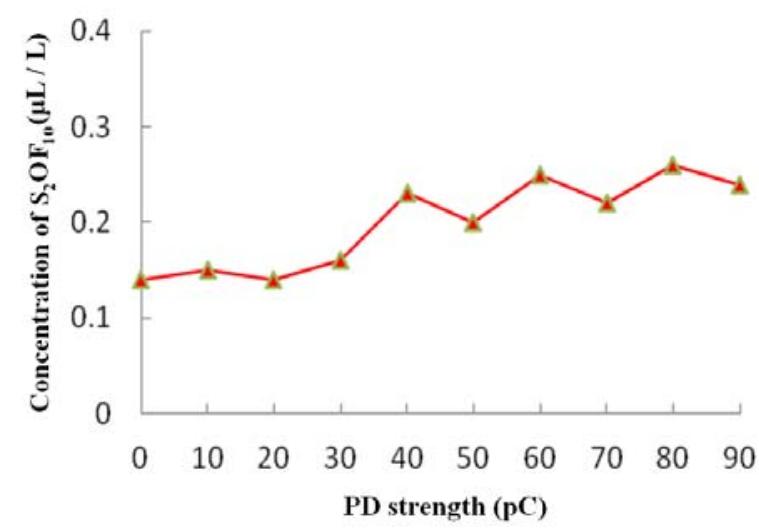

Figure 10. Concentration of S2O2F10 against partial discharge strength under pressure $0.11 \mathrm{MPa}$ (correspond discharge time $1 \mathrm{~h}$ )

2) Relationship between discharge time and main product of $\mathrm{SF}_{6}$ decomposition.

Experimental conditions: gas pressure is $0.21 \mathrm{MPa}$, gas humidity: $175.72 \times 10-6$ (volume fraction concentration) chamber volumes: $0.07 \mathrm{~m}^{3}$, corresponding partial discharge under relatively stable conditions, discharge time: $8 \mathrm{~h}$.

The pressure level in the gas chamber remains constantly at $0.21 \mathrm{MPa}, \mathrm{PD}$ experiment discharge gap is fixed, by adjusting the test voltage, resulting in different partial discharge strength, detect different $\mathrm{SF}_{6}$ decomposition $\left(\mathrm{SOF}_{2} 、 \mathrm{~S}_{2} \mathrm{OF}_{10}\right.$ and $\left.\mathrm{SO}_{2}\right)$ components under PD condition.

As the discharge starts, the discharge voltage $(44.7 \sim$ $46.8 \mathrm{kV})$ remain stable, as the partial discharge strength (45 $\sim 60 \mathrm{pC}$ ) is relatively stable, Figure $11,12,13$ show under the condition of the discharge voltage and partial discharge strength remains stable, the variation of concentration of $\mathrm{SO}_{2}, \mathrm{SOF}_{2}$ and $\mathrm{S}_{2} \mathrm{OF}_{10}$ as a function of voltage application time. The concentration of $\mathrm{SOF}_{2}$ and $\mathrm{S}_{2} \mathrm{OF}_{10}$ grows just as the result of prevent experiment shows, but the range of augmentation is larger. The Decomposition produce a great quantity of $\mathrm{SO}_{2}$, and the component of $\mathrm{SO}_{2}$ increase linearly with time.

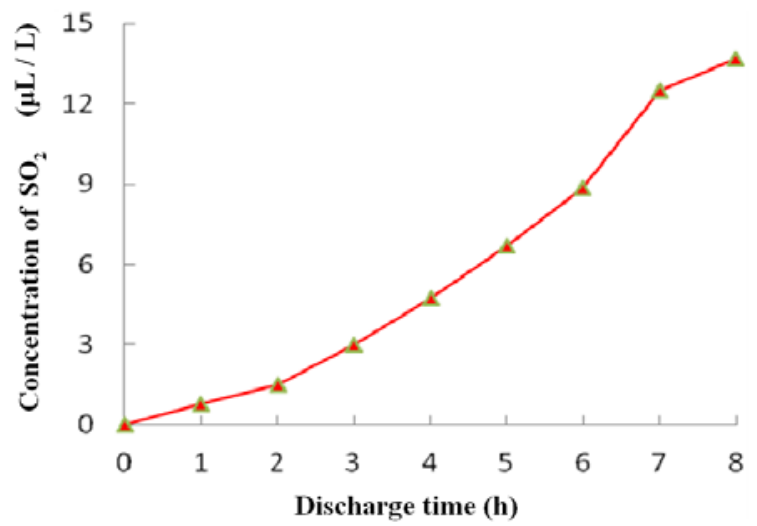

Figure 11. Change in SO2 concentration as a function of voltage application time at the pressure of $0.21 \mathrm{MPa}$ and $\mathrm{PD}$ strength of $45-60 \mathrm{pC}$

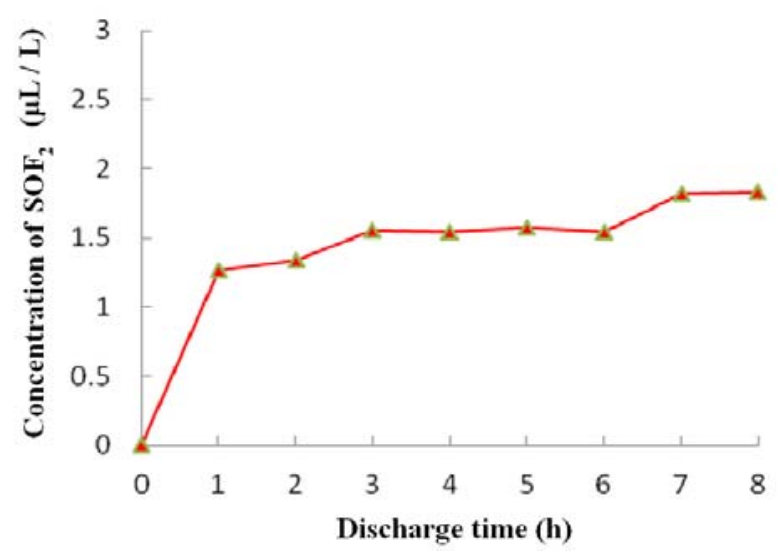

Figure 12. Change in SOF2 concentration as a function of voltage application time at the pressure of $0.21 \mathrm{MPa}$ and $\mathrm{PD}$ strength of $45-60 \mathrm{pC}$ 


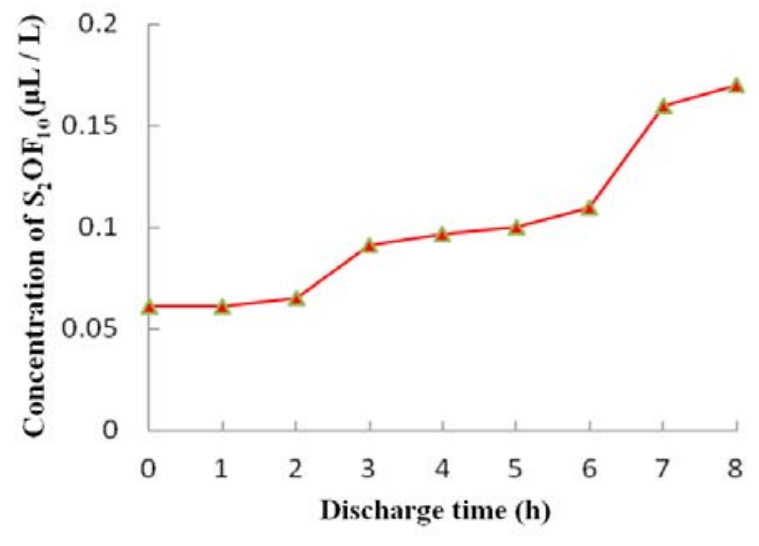

Figure 13. Change in S2OF10 concentration as a function of voltage application time at the pressure of $0.21 \mathrm{MPa}$ and PD strength of $45-60 \mathrm{pC}$

\section{Experimental Studies with Absorbent}

Set adsorbent into the GIS equipment to simulate the actual situation, the discharge experiments is carried out on an environment with absorbent. Analyze the variation of decomposition components under absorbent condition and absorb characteristics of absorbent.

1) Relationship between partial discharge strength and main product of $\mathrm{SF}_{6}$ decomposition under absorbent condition.

Experimental conditions: gas pressure: $0.41 \mathrm{MPa}$, humidity: $113.38 \times 10-6$ (volume fraction concentration), adsorbent: F-03 (in an amount of $10 \%$ by weight of the $\mathrm{SF}_{6}$ gas)

Pressure of $\mathrm{SF}_{6}$ gas is $0.41 \mathrm{MPa}$ which is the same as the actual operating pressure, discharge voltage change basically in the rate of $58.4 \sim 60.1 \mathrm{kV}, \mathrm{PD}$ strength is controlled between $40 \sim 58 \mathrm{pC}$.

During the partial discharge test, decompose component $\mathrm{SOF}_{2}$ produced at the initial of discharge, the content is $1.94 \mu \mathrm{L} / \mathrm{L}$; it keeps a steady content during discharge while trace decreased. $\mathrm{S}_{2} \mathrm{OF}_{10}$ has a stable content, the adsorbent might not adsorb the components otherwise the gas production rate and the adsorption rate $\mathrm{SOF}_{2}$ and $\mathrm{S}_{2} \mathrm{OF}_{10}$ is in balance. Comparing to the experiment without adsorbent, the pressure grows and the content of $\mathrm{SO}_{2}$ decrease. As time passes, the component of $\mathrm{SO}_{2}$ trend to be stable at about $1.7 \mu \mathrm{L} / \mathrm{L}$.

\section{Experimental Absorption}

Experimental conditions: $\mathrm{SF}_{6}$ gas pressure: $0.41 \mathrm{MPa}$, humidity: $202.69 \times 10-6$ (volume fraction concentration), the chamber volume $0.07 \mathrm{~m}^{3}$, test time $15 \mathrm{~h}$ adsorbent is F-03, in an amount of $10 \%$ by weight of the gas.

After stopping discharge, continuously detecting the content of $\mathrm{SF}_{6}$ decomposition products under effect of adsorbent, the interval of gas sampling is 1 hour.

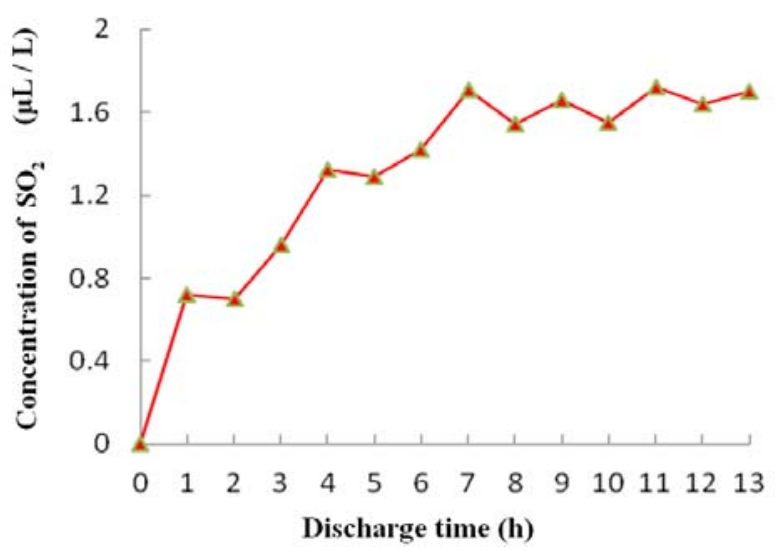

Figure 14. Change in $\mathrm{SO} 2$ concentration as a function of voltage application time under adsorbent conditions, SF6 pressure $0.41 \mathrm{MPa}$ PD strength $43-58 \mathrm{pC}$

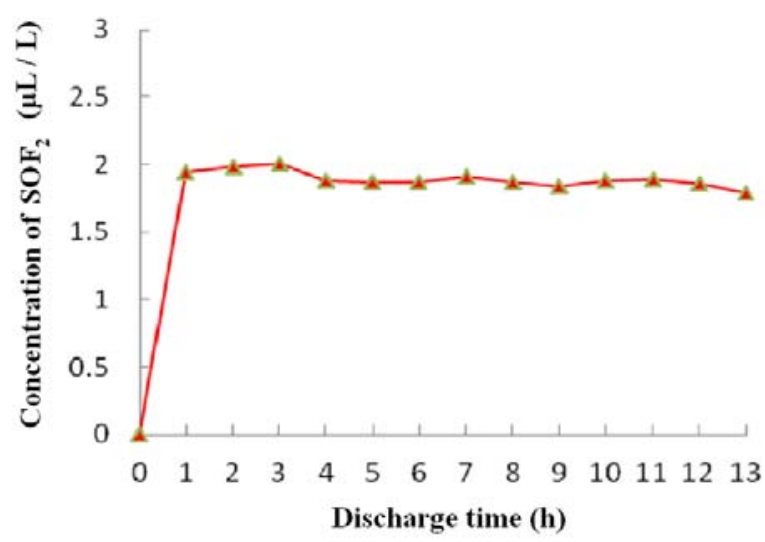

Figure 15. Change in SOF2 concentration as a function of voltage application time under adsorbent conditions, SF6 pressure $0.41 \mathrm{MPa}$ PD strength $43-58 \mathrm{pC}$

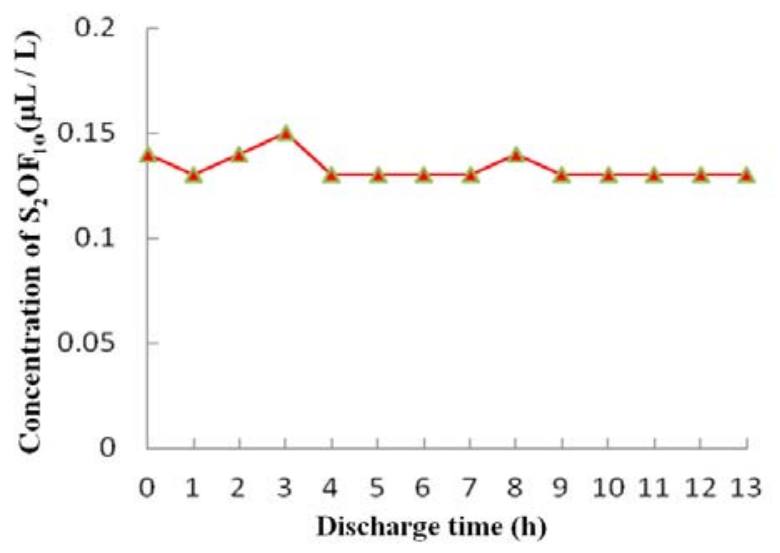

Figure 16. Change in S2OF10 concentration as a function of voltage application time under adsorbent conditions, SF6 pressure $0.41 \mathrm{MPa}$ PD strength $43-58 \mathrm{pC}$

As Table I shows, the contents of air and $\mathrm{S}_{2} \mathrm{OF}_{10}$ didn't change, indicating that the adsorbent dose not adsorb air 
and $\mathrm{S}_{2} \mathrm{OF}_{10} ; \mathrm{SO}_{2}$ is adsorbed completely within $7 \mathrm{~h}$ and $12 \mathrm{~h}$. $\mathrm{SOF}_{2}$ shows a trend of decrease during $12 \mathrm{~h}$ of observation, showing F-03 adsorbent has an obvious adsorption for $\mathrm{SO}_{2}$ gas, and a less obvious adsorption for $\mathrm{SOF}_{2}$.

TABLE 1. ADSORPTION CHARACTERISTICS OF DECOMPOSITION PRODUCTS

\begin{tabular}{ccccc}
\hline $\begin{array}{c}\text { Sampling } \\
\text { time(h) }\end{array}$ & $\begin{array}{c}\text { Air } \\
(\%)\end{array}$ & $\begin{array}{c}\mathrm{SOF}_{2} \\
\mu \mathrm{L} / \mathrm{L}\end{array}$ & $\begin{array}{c}\mathrm{S}_{2} \mathrm{OF}_{10} \\
\mu \mathrm{L} / \mathrm{L}\end{array}$ & $\begin{array}{c}\mathrm{SO}_{2} \\
\mu \mathrm{L} / \mathrm{L}\end{array}$ \\
\hline 0 & 0.07 & 1.89 & 0.10 & 1.22 \\
1 & 0.07 & 1.89 & 0.10 & 1.22 \\
2 & 0.06 & 1.87 & 0.10 & 0.81 \\
3 & 0.06 & 1.91 & 0.11 & 0.81 \\
4 & 0.06 & 1.86 & 0.11 & 0.61 \\
5 & 0.06 & 1.91 & 0.12 & 0.61 \\
6 & 0.06 & 1.89 & 0.12 & 0.19 \\
7 & 0.06 & 1.84 & 0.13 & 0.19 \\
8 & 0.06 & 1.86 & 0.12 & 0 \\
9 & 0.06 & 1.79 & 0.13 & 0 \\
\hline
\end{tabular}

\begin{tabular}{lllll}
\hline 10 & 0.06 & 1.78 & 0.13 & 0 \\
11 & 0.06 & 1.72 & 0.13 & 0 \\
12 & 0.06 & 1.72 & 0.13 & 0 \\
13 & 0.06 & 1.61 & 0.13 & 0 \\
14 & 0.06 & 1.60 & 0.13 & 0 \\
15 & 0.06 & 1.59 & 0.13 & 0 \\
\hline
\end{tabular}

\section{E. Experimental Results Statistics and Analysis}

Set bus-bar spikes on fault mode of GIS shell discharge on $126 \mathrm{kV}$ GIS partial discharge experimental platform. Carried out discharge experiments without adsorbent at pressure state of $0.11 \mathrm{MPa}$ and $0.21 \mathrm{MPa}$ and experiment with adsorbent condition at pressure state of $0.41 \mathrm{MPa}$. Continuously detect the decomposition content after stopping the discharge. The discharge voltage, maximum partial discharge strength and maximum decomposition content under 3 experimental conditions are shown in Table II.

TABLE II. DISCHARGE VOLTAGE UNDER DIFFERENT EXPERIMENTAL CONDITIONS, THE MAXIMUM VOLUME AND THE DECOMPOSITION PRODUCTS BUREAU MAXIMUM CONTENT

\begin{tabular}{ccccccc}
\hline \multirow{2}{*}{ Adsorbent } & \multirow{2}{*}{$\mathrm{P}(\mathrm{MPa})$} & Voltage $(\mathrm{kV})$ & $\mathrm{Qmax}(\mathrm{pC})$ & \multicolumn{3}{c}{ Max. Content $(\mu \mathrm{L} / \mathrm{L})$} \\
\cline { 5 - 7 } & & & & $\mathrm{SOF}_{2}$ & $\mathrm{~S}_{2} \mathrm{OF}_{10}$ & $\mathrm{SO}_{2}$ \\
\hline \multirow{2}{*}{ No } & 0.11 & 40 & 90 & 1.89 & 0.26 & 37.62 \\
\multirow{2}{*}{ Yes } & 0.21 & 45 & 80 & 1.88 & 0.22 & 24.96 \\
\hline
\end{tabular}

When partial discharge occurs, electrons are accelerated in an electric field, form high-energy electrons, electron collision induced gas ionization, under non-equilibrium conditions, the electron temperature is much higher than the gas temperature, electron energy has a wide distribution, there exist the energetic electrons which has several times higher energy than the energy of average electrons. During the partial discharge, the average energy of electron could reach $5.03 \mathrm{eV}$, which is higher than the energy of S-F bond. Electron impact $\mathrm{SF}_{6}$ molecules lead to molecular orbital fracture, producing electrons, ions, free radicals and other unstable chemical group, by attachment or recombination regrouping decomposition products.

When high-energy electron bombardment $\mathrm{SF}_{6}, \mathrm{O}_{2}$, it can be gradually decompose $\mathrm{SF}_{5}^{-}, \mathrm{SF}_{4}^{-}, \mathrm{SF}_{3}^{-}, \mathrm{SF}_{2}^{-}$and $\mathrm{O}^{-}$, these chemical group has further reaction to produce $\mathrm{SF}_{5}$, $\mathrm{SF}_{4}, \mathrm{SF} 3$ and $\mathrm{SF}_{2}$. When there exist no impurities in the gas or container surface, decomposition products of $\mathrm{SF}_{6}$ will quickly compounded. When $\mathrm{O}_{2}$ exists, the process will generate thioredoxin fluoride, such as $\mathrm{SOF}_{2}, \mathrm{~S}_{2} \mathrm{OF}_{2}, \mathrm{~S}_{2} \mathrm{OF}_{10}$. $\mathrm{SOF}_{2}$ and $\mathrm{H}_{2} \mathrm{O}$ react to form $\mathrm{SO}_{2}$. The experiment verifies the production of $\mathrm{SOF}_{2}, \mathrm{~S}_{2} \mathrm{OF}_{10}$ and $\mathrm{SO}_{2}$.

\section{CONCLUSION}

The partial discharge experiment on $126 \mathrm{kV}$ GIS partial discharge experimental platform detecting the $\mathrm{SF}_{6}$ decomposition production, making following conclusions:

a. Initial discharge voltage rise up as the pressure increase. While keep the initial discharge voltage stable, the PD strength decrease as the pressure increases.

b. Main products of the $\mathrm{SF}_{6}$ gas decomposition are $\mathrm{SO}_{2}$ and $\mathrm{SOF}_{2}$, content of $\mathrm{SO}_{2}$ increases as the discharge time rise, resulting in production of a small amount of $\mathrm{S}_{2} \mathrm{OF}_{10}$.

c. After the installation of the adsorbent, the content of $\mathrm{SOF}_{2}$ and $\mathrm{S}_{2} \mathrm{OF}_{10}$ keep stable after the discharge stopped. $\mathrm{SO}_{2}$ is adsorbed completely within $7 \mathrm{~h}$ and $12 \mathrm{~h}$. $\mathrm{SOF}_{2}$ shows a trend of decrease during $12 \mathrm{~h}$, showing F-03 adsorbent has an obvious adsorption for $\mathrm{SO}_{2}$ gas, and a less obvious adsorption for $\mathrm{SOF}_{2}$.

\section{REFERENCES}

[1] IEC 604802004 Guidelines for the checking and treatment of sulfur hexafluoride $\left(\mathrm{SF}_{6}\right)$ taken from electrical equipment and specification for its re-use

[2] GB/T 12022-2006 Industrial sulfur hexafluoride

[3] DL/T 920-2005 Sulfur hexafluoride gas, air, carbon tetrafluoride gas chromatographic method

[4] YAN Xianglian, WANG Chengyu, JI Yansong, GUO Yuanyuan, Application of Decomposition Products Detection of $\mathrm{SF}_{6}$ in Switchgears, Power System Technology, 2010, 34(9)

[5] LIU Yong, YIN Hua, YAO Qiang, QIU Ni, The Application of Gas Analysis Technology to Fault Location and Fault Diagnosis of GIS, High Voltage Apparatus, 2009, 3 
[6] JI Yan-song, WANG Cheng-yu, YANG Ren, YAN Xiang-lian, Measuring Technique of $\mathrm{SF}_{6}$ Decomposition Products and Its Application to Fault Diagnosis of GIS, High Voltage Apparatus, 2011,2

[7] YAN Xianglian, WANG Chengyu, YANG Ren, JI Yansong, Study on Fault Diagnosis of High Voltage Switchgears by Decomposition Products of $\mathrm{SF}_{6}$, Power System Technology, 2011, 12

[8] F. Y. Chu, J. M. Braun, and R. Seethapathy, "Degradation Mechanisms for Epoxy Insulators Exposed to $\mathrm{SF}_{6}$ Arcing By-Products," Proc. IEEE Intl. Symp. Electr. Insul., June 1986.

[9] C. Boudene, J-L Cluet, G. Keib, and G. Wind, "Identification and Study of Some Properties of Compounds Resulting from the
Decomposition of $\mathrm{SF}_{6}$ under the Effect of Electrical Arcing in Circuit-Breakers," Revue Generale Electricite - Special Issue, June 1974

[10] J. M. Braun and F. Y. Chu, "Novel Low-Cost $\mathrm{SF}_{6}$ Arcing By-Product Detectors for Field Use in GIS," IEEE PES Summer Power Meeting, Vancouber, B.C., Paper 85 SM³69-4, July 1985.

[11] A. Hollinger. "Analyzer for Decomposition Products and Moisture in $\mathrm{SF}_{6}$ Gas," Can. Electr. Assoc. Final Report 086-T-176, June 1984.

[12] I. Sauers, H. W. Ellis, L. G. Christophorou, G. D. Griffin, and C. E. Easterly, "Spark Decomposition of $\mathrm{SF}_{6}$; Toxicity of By-Products," Oak Ridge National Laboratory Report ORNL/TM- 9062, October 1984. 